\title{
TRANSFORMASI LAYANAN DISABILITAS PADA PERPUSTAKAAN PERGURUAN TINGGI DI ERA 4.0
}

\author{
Wahyuni \\ Perpustakaan Universitas Airlangga \\ e-mail: yuni.asadullah@gmail.com
}

\begin{abstract}
ABSTRAK
Perkembangan teknologi informasi melahirkan revolusi industri yang saat ini memasuki era revolusi industri 4.0. Revolusi industri 4.0 berhubungan dengan big data yang berkembang sangat pesat sehingga pertumbuhan teknologi sangat cepat. Hal ini berdampak juga dalam dunia perpustakaan, yang tentunya harus bisa menyesuaikan dengan zaman dalam memberikan layanan kepada pemustaka. Pemustaka perpustakaan saat ini diharapkan juga mampu menjadi perpustakaan ramah bagi penyandang disabilitas, sehingga penyandang disabilitas juga bisa memanfaatkan perpustakaan dengan nyaman. Perpustakaan diharapkan bertransformasi dengan menyediakan kemudahan akses informasi kepada penyandang disabilitas, dengan bantuan teknologi informasi, sarana dan prasarana, fasilitas yang sesuai dengan karakteristik penyandang disabilitas. Perpustakaan juga mendukung tersedianya pustakawan yang siap membantu pemustaka disabilitas dengan memberikan pelatihan bagaimana memberikan pelayanan bagi penyandang diabilitas.
\end{abstract}

Kata kunci: disabilitas, perpustakaan perguruan tinggi, revolusi industry 4.0

\section{PENDAHULUAN}

Globalisasi telah memasuki babak baru yang namanya revolusi industri 4.0, revolusi industri 4.0 ditandai dengan adanya perkembangan internet yang sangat pesat serta sebaran informasi data yang jumlahnya jutaan, sehingga mengakselerasi pertumbuhan teknologi (Puspitasari, 2019). Kehadiran industri 4.0 ini juga berpengaruh dalam lembaga penyedia informasi yaitu perpustakaan. Undang-undang No 43 Tahun 2007 Pasal 3 tentang Perpustakaan menyatakan bahwa perpustakaan berfungsi sebagai wahana pendidikan, penelitian, pelestarian, informasi dan rekreasi untuk meningkatkan kecerdasan dan kebudayaan bangsa. Hal ini menuntut perpustakaan beradaptasi dengan perkembangan teknologi informasi agar dapat memenuhi kebutuhan informasi sesuai zamannya, termasuk perpustakaan perguruan tinggi.

Perpustakaan perguruan tinggi mempunyai pemustaka yang beragam yaitu sivitas akademika (mahasiswa, dosen, staff), masyarakat umum, baik yang secara fisik dan mental normal maupun yang menyandang disabilitas. Peraturan Menteri Pendidikan dan Kebudayaan RI No. 46 tahun 2014 tentang pendidikan khusus, pendidikan layanan khusus dan atau pembelajaran layanan khusus pada pendidikan tinggi pasal 1 menyatakan bahwa pendidikan khusus pada perguruan tinggi adalah pelaksana pendidikan di perguruan tinggi bagi mahasiswa yang mengalami hambatan fisik, emosi, mental, sosial, dan/atau memiliki potensi kecerdasan dan bakat istimewa. Penyandang disabilitas berkesempatan melanjutkan pendidikannya sampai ke jenjang perguruan tinggi.

Di era revolusi industri 4.0 perkembangan teknologi, informasi dan komunikasi semakin cepat. Perkembangan ini menjadi pemacu perpustakaan perguruan tinggi untuk memberikan kemudahan layanan kepada pemustaka dengan menyediakan layanan berbasis teknologi informasi, sehingga memudahkan pemustaka memperoleh informasi yang dibutuhkan. Kemudahan itu tentunya juga harus bisa dirasakan oleh pemustaka penyandang disabilitas, sehingga terciptalah perpustakaan perguruan tinggi ramah difabel di era 4.0.

\section{METODE PENELITIAN}

Menurut Sugiyono (2013:2), Metode penelitian pada dasarnya merupakan cara ilmiah untuk mendapatkan data 
dengan tujuan dan kegunaan tertentu. Berdasarkan hal tersebut terdapat empat kata kunci yang perlu diperhatikan yaitu cara ilmiah, data, tujuan dan kegunaan. Penelitian ini menggunakan penelitian kualitatif bersifat studi pustaka dengan mencari literatur berupa buku, jurnal, penelitian maupun undang-undang yang sesuai dengan penelitian ini.

\section{PEMBAHASAN}

\section{Penyandang Disabilitas}

Difabel adalah singkatan dari differently abled people (perbedaan kemampuan) atau berkebutuhan khusus untuk mengganti istilah penyandang cacat. Dalam UndangUndang Republik Indonesia No. 8 Tahun 2016 tentang Penyandang Disabilitas disebutkan bahwa penyandang disabilitas adalah setiap orang yang mengalami keterbatasan fisik, intelektual, mental, dan/atau sensorik dalam jangka waktu lama yang dalam berinteraksi dengan lingkungan dapat mengalami hambatan dan kesulitan untuk berpartisipasi secara penuh dan efektif dengan warga negara lainnya berdasarkan persamaan hak. Pertimbangan yang menjadi latar belakang pengesahan undang-undang ini salah satunya mewujudkan kesamaan hak dan kesempatan bagi penyandang disabilitas menuju kehidupan sejahtera, mandiri, dan tanpa diskriminasi. Undang-undang tersebut menyatakan bahwa penyandang mempunyai hak dan kesempatan yang sama termasuk dalam pendidikan dan memperoleh pelayanan publik.

Difabel disebutkan dalam Peraturan Pemerintah Nomor 72 tahun 1991 adalah mereka yang memiliki jenis kelainan fisik dan mental atau kelainan perilaku. Kelainan fisik meliputi: tunanetra, tunarungu, dan tunadaksa. Sementara kelainan mental meliputi: tunagrahita ringan dan tunanagrahita sedang, sedangkan kelainan perilaku meliputi tunalaras. Berdasarkan pendapat diatas dapat disimpulkan bahwa penyandang disabilitas adalah seorang yang potensial bermasalah. Namun, apabila mendapatkan layanan pendidikan dan informasi secara tepat, potensi mereka akan dapat berkembang secara optimal. Selanjutnya, harus disadari bahwa keterbatasan secara fisik dan mental tidaklah menghapus mereka sebagai warga negara, termasuk pula hak untuk mengakses informasi (Safrudin Aziz, 2014).

Hak-hak penyandang disabilitas untuk mendapatkan informasi dapat terpenuhi dengan tersedianya layanan informasi yang memadai sesuai dengan karakteristik dan kebutuhan penyandang disabilitas. Perpustakaan sebagai pusat informasi diharapkan mampu memfasilitasi kesesuaian fasilitas pemustaka difabel agar bisa memanfaatkan layanan perpustakaan dengan maksimal dan lebih nyaman.

\section{Perpustakaan Perguruan Tinggi}

Peraturan Pemerintah Nomor 24 Tahun 2014 tentang Perpustakaan menyatakan bahwa Perpustakaan Perguruan tinggi adalah perpustakaan yang merupakan bagian integral dari kegiatan pendidikan, penelitian dan pengabdian kepada masyarakat dan berfungsi sebagai pusat sumber belajar untuk mendukung tercapainya tujuan pendidikan yang berkedudukan di perguruan tinggi. Perpustakaan perguruan tinggi dalam melaksanakan fungsinya berperan membantu melaksanakan Tri Dharma Perguruan Tinggi (pengajaran, penelitian, dan pengabdian kepada masyarakat), lazimnya melayani kebutuhan masyarakat akademis, seperti dosen, mahasiswa, peneliti, dan sebagainya.

Perpustakaan perguruan tinggi di era 4.0 diharuskan juga bertranformasi mengikuti perkembangan teknologi internet dan digital. Memberikan kemudahan akses semua pemustaka yang menggunakan perpustakaan dengan bantuan teknologi informasi yang diterapkan di perpustakaan. Untuk memenuhi tujuan tersebut, tentunya perpustakaan perguruan tinggi diharapkan lebih baik, bahkan lebih produktif dibandingkan perpustakaan yang lain, khususnya koleksi yang selalu berkembang, baru, up to date sehingga mampu menjawab persoalan dan tantangan zaman (Safrudin Aziz, 2014).

\section{Perpustakaan Ramah Disabilitas Di Era 4.0}

Era revolusi industri 4.0 memberikan dampak cukup signifikan pada perpustakaan. Perpustakaan perlu membuat perubahan (transformasi) dalam semua kegiatan layanan perpustakaan agar dapat mempertahankan eksistensinya. Perpustakaan bisa melakukan perubahan baik dari segi layanan, sarana dan prasarana, fasilitas, termasuk bertransformasi menjadi perpustakaan ramah disabilitas guna menyongsong revolusi industri 4.0. Segala aspek untuk mendukung terciptanya perpustakaan ramah difabel harus dipersiapkan. Menurut IFLA (http:// archive.ifla.org), secara umum perpustakaan harus memperhatikan akses fisik yang mencakup:

1. Area parkir, lingkungan, dan seluruh area perpustakan harus dapat diakses bagi orang-orang yang menggunakan kursi roda, alat bantu, atau alat bantu mobilitas lainnya.

2. Pintu masuk, yakni revolving pintu hendaknya bisa tetap terbuka secara otomatis dan tombol lift berada 
diketinggian yang tetap untuk orang kursi roda dan pintu otomatis hendaknya bisa tetap terbuka cukup lama.

3. Ruang perpustakaan, artinya ruang perpustakaan hendaknya diatur sedemikian rupa serta diberi tandatanda yang jelas sehingga difabel yang menggunakan kursi roda bisa mengakses informasi secara leluasa.

4. Kamar kecil, setiap perpustakaan harus memiliki setidaknya satu toilet disesuaikan untuk pemustaka difabel yang berarti ukurannya cukup besar sehingga kursi roda bisa masuk dan bergerak dengan nyaman.

5. Meja sirkulasi, meja sirkulasi sebaiknya dekat dengan pintu masuk. Meja sirkulasi hendaknya disesuaikan dengan pemustaka difabek sehingga pustakawan dapat berkomunikasi dengan pemustaka yang sedang duduk di kursi roda.

6. Children department, artinya bagi pemustaka anakanak yang memiliki berbagai jenis gangguan, mereka seharusnya ditempatkan pada layanan informasi secara khusus.

7. Ruang baca dan dengar bagi pemustaka difabel, pemustaka dengan disabilitas membaca memerlukan perhatian khusus ketika mereka mendatangi perpustakaan.

8. Komputer, komputer pada perpustakaan hendaknya dapat digunakan oleh setiap pemustaka difabel.

Pustakawan perpustakaan perguruan tinggi berperan memberikan kontribusi di lingkungan universitas, baik untuk mendukung kegiatan akademik maupun riset sivitas akademika. Disisi lain pustakawan juga berhadapan dengan revolusi industri yang bergerak dengan cepat serta serta berhadapan dengan pemustaka generasi millennial yang memiliki perbedaan cara belajar dan cara memperoleh informasi yang mereka butuhkan. Generasi millennial sangat bergantung pada gadget untuk mencari informasi dengan cepat. Pada kondisi ini tentunya pustakawan harus siap menguasai teknologi informasi dan memiliki softskill untuk memudahkan dalam mencari informasi yang dibutuhkan pemustaka.

Secara khusus pustakawan juga sangat diperlukan pemustaka millennial penyandang disabilitas di perpustakaan perguruan tinggi. Semua pustakawan harus memiliki pengetahuan tentang jenis disabilitas dan bagaimana memberikan pelayanan terbaik untuk penyandang disabilitas. Menurut (Irvall: 2005) contoh pelatihan yang tepat untuk pustakawan dalam memberikan layanan kepada disabilitas yaitu:

1. Mengundang pemustaka disabilitas dalam rapat pustakawan untuk membicarakan kebutuhan mereka sebagai pemustaka.
2. Bagikan email dan atau informasi lain kepada staf secara berkala tentang layanan perpustakaan untuk kelompok disabilitas tertentu.

3. Sertakan informasi layanan khusus untuk pemustaka

4. Memberikan orientasi kepada staff pustakawan baru tentang layanan untuk disabilitas.

Pustakawan yang sudah dilatih akan mempermudah pelayanan kepada penyandang disabilitas. Selain itu, pustakawan juga dituntut menguasai teknologi dan bisa memberikan layanan literasi informasi untuk penyandang disabilitas. Layanan literasi informasi bagi penyandang disabilitas tentunya berbeda sesuai dengan jenis disabilitas yang dimiliki.

Fasilitas dan layanan informasi juga perlu disediakan perpustakaan perguruan tinggi untuk membantu kemandirian penyandang disabilitas (http://www.ala. org), diantaranya:

1. Komputer

Teknologi bantuan (juga disebut adaptif) adalah solusi elektronik yang memungkinkan para penyandang cacat hidup mandiri. Tunanetra dapat mendengar teks layar komputer, dan orang tunanetra dapat memperbesar teks, memungkinkan pembacaan independen. Orangorang yang tidak dapat memanipulasi mouse dapat memasukkan data, dan mereka yang secara fisik tidak dapat mendengar prompt komputer dapat melihat prompt. Ada juga perangkat lunak komputer yang membantu orang dengan perbedaan belajar melihat dan mendengar informasi yang ditampilkan di layar. Untuk membantu pemustaka dengan kebutaan atau gangguan visual ada beberapa solusi perangkat keras dan perangkat lunak yang paling umum, yaitu:

a. ZoomText Xtra layar perbesaran perangkat lunak - program ini memungkinkan pelanggan dengan penglihatan rendah untuk mengakses informasi komputer dengan memperbesar tampilan layar atau menyesuaikan tampilan untuk mengakomodasi ketidakmampuan mereka.

b. Pembaca layar JAWS - program ini memungkinkan individu yang tunanetra atau tunanetra dapat mengakses informasi di layar komputer melalui output suara.

c. Pembaca teks Buku Terbuka - membantu mereka yang memiliki penglihatan rendah atau tanpa penglihatan. Memindai teks yang dicetak dan mengucapkan teks tersebut melalui ucapan sintetik. 
d. Duxbury Braille Translating Software - program yang, seperti pengolah kata, memungkinkan pengguna mengetik teks, lalu menerjemahkannya ke dalam Braille. Embosser Braille menghasilkan hardcopy.

e. Braille embosser - mirip dengan printer, embosser akan mencetak Braille Tingkat II di atas kertas, memungkinkan pelanggan membuat salinan dokumen. Jika Braille hard-copy tidak tersedia, itu memungkinkan pengguna untuk menyimpan dokumen ke USB flash drive.

f. Perangkat lunak Talking Typer - Talking Typer, dari American Printing House (APH), adalah program pengetikan guru yang dirancang khusus untuk mereka yang buta, memiliki penglihatan rendah, atau belajar dengan kecepatan yang berbeda. Program ini menyediakan instruksi dan tutorial audio.

g. Penting untuk tidak melupakan barang-barang dasar seperti kaca pembesar genggam, penuntun tanda tangan, pulpen felt-tip, dan perangkat pembesaran besar seperti pembesar televisi sirkuit tertutup (CCTV). Sistem ini menggunakan lensa kamera video untuk memperbesar teks dari tiga hingga tiga puluh kali ukuran teks normal.

Kiat untuk membantu pemustaka dengan gangguan pendengaran atau ketulian. Banyak pengguna komputer yang tuli atau memiliki gangguan pendengaran tidak akan mengalami masalah dalam menggunakan komputer itu sendiri. Masalah akan muncul dari program dan situs web yang memiliki isyarat audio, solusinya yaitu:

a. Sound Sentry - ditemukan di semua program Microsoft Windows dan Vista serta di komputer Apple program ini memungkinkan pengguna yang tidak dapat mendengar bunyi peringatan tertanam dari produk Microsoft untuk melihatnya sebagai flash.

b. Pesan Instan - teknologi arus utama ini memungkinkan staf dan pelanggan yang tidak dapat mendengar untuk "berbicara" satu sama lain.

Kiat untuk membantu pemustaka dengan Perbedaan Pembelajaran. Orang dengan cacat fisik mungkin memerlukan bantuan dalam melakukan beberapa tugas fisik yang terlibat dalam menggunakan komputer. Orang yang menggunakan kursi roda atau skuter akan membutuhkan stasiun kerja yang kokoh dan aman. Tinggi meja dan posisi monitor harus disesuaikan. Item berikut meningkatkan kegunaan dan keamanan komputer: a. Perangkat input khusus seperti trackball, joystick, sakelar, bantalan sentuh, dan keyboard yang ditambah (keyboard mikro atau keyboard berukuran besar dengan tombol yang diperbesar)

b. Madentec Tracker - pengguna mengenakan titik reflektif kecil di dahi atau kacamata. Kamera/ pelacak komputer memungkinkan pengguna untuk memanipulasi kursor melalui gerakan kepala.

c. Softype - utilitas perangkat lunak yang menggantikan fungsi keyboard standar dengan keyboard layar penuh berfitur.

\section{Electronic Book}

Penyandang disabilitas juga bisa memanfaatkan informasi diperpustakaan dalam bentuk e-book dengan bantuan sarana komputer atau laptop yang sudah dilengkapi program pembaca. DAISY, EPUB, dan TXT adalah format $e$-book yang paling mudah diakses, sementara PDF dapat diakses dengan mudah diakses dan dokumen HTML sederhana biasanya disediakan format $e$-teks yang dapat diakses.

a. DAISY (Sistem Informasi Aksesibilitas Digital) adalah buku teks digital yang dirancang dan dikembangkan untuk orang-orang dengan cacat cetak. Dapat didengarkan dengan menggunakan Pemain buku digital DAISY yang mengubah teks menjadi ucapan. Pengguna dengan perangkat seluler juga dapat menginstal aplikasi untuk membaca $e$-book DAISY. DAISY mendukung gambar dan teks dengan audio dan memungkinkan navigasi konten.

b. EPUB (publication Elektronik) adalah tujuan umum format dan dapat digunakan untuk berbagai jenis publikasi seperti buku, majalah, jurnal, dan sejenisnya dokumen elektronik. Dikembangkan oleh Internasional Forum Penerbitan Digital (IDPF), EPUB menggunakan teknologi mirip dengan HTML dan dimaksudkan sebagai perangkat independen.

c. File teks (TXT) adalah format teks biasa dan sangat sederhana dianggap sebagai format universal. Ini format bebas DRM dan dapat dibaca oleh program apa pun.TXT memiliki keterbatasanitu tidak mendukung format seperti huruf tebal atau miring, juga tidak mendukung media kaya atau interaktivitas konten. Dokumen TXT dapat dibaca oleh pembaca layar.

d. Perusahaan Adobe merupakan salah satu format yang digunakan paling luas untuk 
menyebarluaskan dokumen. Penerbit e-book biasanya menggunakan format ini untuk konten teks lengkap. PDF memungkinkan penerbit untuk menanamkan berbagai fitur seperti font, tautan kaya, resolusi tinggi gambar, dan tata letak untuk presentasi. Sebagian besar perangkat elektronik dilengkapi dengan aplikasi untuk membaca file PDF.

e. HTML (Hypertext Markup Language, juga dilambangkan dengan.htm atau.html) adalah bahasa markup yang biasanya digunakan untuk membangun situs web. Biasanya file HTML dapat dibaca menggunakan browser web. (Junus, S.G.Ranti: 2012)

\section{KESIMPULAN}

Revolusi industri mempunyai pengaruh yang besar dalam perubahan dalam segala aspek kehidupan, perpustakan menjadi salah satu yang terdampak revolusi industri yang saat ini memasuki revolusi industri 4.0. Teknologi informasi yang sangat cepat dan pesat menjadi bagian dari revolusi industri 4.0. Perpustakaan perguruan tinggi menjadi salah satu pusat informasi yang mempunyai pemustaka yang sangat beragam, baik sivitas akademika (dosen, mahasiswa dan staff) maupun masyarakat umum. Pemustaka perpustakaan perguruan tinggi juga berasal dari pemustaka yang normal secara fisik dan mental maupun penyandang disabilitas. Oleh karenanya perpustakaan perguruan tinggi juga harus bersiap menjadi perpustakaan yang ramah disabilitas guna memberikan kenyamanan memperoleh informasi bagi penyandang disabilitas di era revolusi industri 4.0. Perpustakaan perguruan tinggi ramah difabel di era 4.0 yaitu perpustakaan yang memiliki sarana prasarana, fasilitas, layanan, pustakawan serta teknologi informasi yang sesuai dengan karakteristik dan kebutuhan penyandang disabilitas.

\section{DAFTAR PUSTAKA}

Aziz, Safrudin. 2014. Perpustakaan Ramah Difabel. Yogyakarta: Ar-Ruzz Media.

Irvall, Brigitta. 2005. Access to Libraries for Pearson with Disabilities-Checklist. IFLA Professionals Reports, No. 89

Junus, S.G Ranti. 2012. E-books and E-readers for Users with Print Disabilities. Library Technology Reports

Peraturan Menteri Pendidikan dan Kebudayaan RI No. 46 tahun 2014 tentang pendidikan khusus, pendidikan layanan khusus dan atau pembelajaran layanan khusus pada pendidikan tinggi

Peraturan Pemerintah Nomor 72 tahun 1991 tentang Pendidikan Luar Biasa

Peraturan Pemerintah Nomor 24 Tahun 2014 tentang Perpustakaan

Puspitasari, Dewi. 2019. Pustakawan Tangguh Menghadapi Era Disrupsi. Surakarta: Yuma Pustaka

Sugiyono. 2013. Metode Penelitian Kuantitatif, Kualitatif dan R\&D.Bandung: Alfabeta.CV

Undang-Undang Republik Indonesia No. 8 Tahun 2016 tentang Penyandang Disabilitas

Undang-undang No 43 Tahun 2007 Pasal 3 tentang Perpustakaan

http://www.ala.org/asgcla/resources/tipsheets/assistivetechnologies. Assistive Technology: What You Need to Know Library. Diakses 20 Desember 2019, 13.13 WIB.

(http://archive.ifla.org). Diakses 17 Desember 2019, 09.00 WIB. 